\title{
USING THE 'F'-WORD IN PRIMATOLOGY
}

by

\author{
JOAN B. SILK \\ (Department of Anthropology, University of California, Los Angeles, CA 90095, USA)
}

(Acc. 30-XI-2001)

Primatologists have recently begun to use the word 'friendship' to describe close, affiliative relationships among monkeys and apes. This seems to be part of a growing backlash against what some researchers see as a narrowminded preoccupation with the negative aspects of animal behavior, such as competition, conflict, manipulation, coercion, and deception (e.g. de Waal, 1996). There is a new emphasis on more positive features of animal behavior, such as coordination, negotiation, reconciliation, and cooperation, that animals use to mitigate conflicts of interest and resolve conflicts. In animal species, the formation of affiliative social bonds may constitute an important adaptive strategy (Cheney et al., 1986). This point of view has generated considerable interest in describing social relationships among nonhuman primates in quantitative and qualitative terms; and the term 'friendship' has entered the primatological lexicon.

Friendship is the F-word; a word that many primatologists have been reluctant to use in print though we may use it freely when we chat with our colleagues about the animals that we study. When we do use the term in academic venues, we feel compelled to cloak it in italics, as if this gives us some indemnity against charges of anthropomorphism or lack of rigor. But lately primatologists have become more relaxed about using the F-word, even dropping the protective italics.

The use of ordinary English words, like altruism, kidnapping, reconciliation, and rape, to describe behavioral phenomena is a common, but sometimes controversial, practice. It is convenient to use these kinds of terms because they are easy to remember and provide a useful shorthand for categorizing behaviors as functional units. However, it is problematic when the 
technical definitions that biologists assign words like these differ substantially from the meanings (or connotations) that the same words have in ordinary usage. The most useful labels are ones that capture critical elements of the phenomena and provide accurate insight about its function.

This is fine in theory, but problematic in practice. It means that we ought to have a fairly good understanding of the function of a behavior before we label it. However, we often find it useful to name a behavior well before we fully understand it. Of course, we can change a label if we discover that it is inappropriate. Consider, for example, the terms that we have used for interactions directed toward young infants. Monkeys, particularly females, seem to find young infants extremely attractive, and frequently approach the mother and try to touch, muzzle, inspect, groom, and pull on the newborn infant. These behaviors have been variously described as 'aunting' (Rowell et al., 1964), 'allomaternal care' (O’Brien \& Robinson, 1991, Stanford, 1992), 'infant grabbing' (Small \& Smith, 1981) and 'kidnapping' (Silk, 1980). All of these terms imply something about the putative function of the behavior. Clearly, aunting implied that these behaviors had benign outcomes for the infant, while kidnapping implied that the behavior was potentially harmful to the infant. However, no single interpretation is necessarily correct in every case (Hrdy, 1976; Paul, 1999), and a more neutral term has been introduced, 'infant handling' (Maestripieri, 1994). Although we can simply relabel behaviors as our understanding of their function changes, this is not always effective. Labels seem to be strangely persistent. The terms, aunting and kidnapping, continued to be used long after we had good reasons to suspect that the connotations of these words were not appropriate for the phenomena that we observe.

The goal of this paper is to consider some of the implications of using the word 'friendship' to describe close social relationships among nonhuman primates. The use of this term implies that the social bonds formed by some pairs of nonhuman primates are roughly analogous to human friendships and serve similar emotional, psychological, and adaptive functions. This raises several related questions: (1) What kinds of properties do relationships characterized as friendships have? (2) How can we study these kinds of relationships in nonhuman primates? (3) What evolutionary forces shape the dynamics of these kinds of relationships in primates (including humans)? (4) What are the adaptive consequences of friendship? 
For convenience, I will use the terms social bond and social relationship interchangeably. Lacking a clear biological definition of either term, it may seem arbitrary to treat them as synonyms. However, their English meanings are quite similar. My dictionary (Random House Unabridged Dictionary, 1973), defines relationship as follows: "1. A connection, association or involvement, 2. Connection by blood or marriage, 3. An emotional or other connection between people." Bond is defined as: "(1) something that binds, fastens, confines, or holds together, (2) a cord, rope, band, or ligament, (3) something that binds a person or persons to a certain line of behavior, (4) something, as an agreement or friendship, that unites individuals or peoples into a group." Thus, it seems reasonable to treat these words as synonyms here.

\section{Properties of human friendships}

If we want to think about implications of using the term friendship to describe certain kinds of social relationships in nonhuman primate groups, it makes sense to begin by reviewing what we mean by the term when we use it to describe our own friendships. Friendship is not an easy concept to define precisely. However, useful insight about the essential properties of friendship comes from a large body of research on friendship conducted by social psychologists and sociologists. There is a general consensus that friendships are intimate, supportive, egalitarian relationships. Companionship, trust, loyalty, commitment, affection, acceptance, sympathy, and concern for the other's welfare are also important components of friendship (e.g. Reisman, 1981; Davis \& Todd, 1985; Veniegas \& Peplau, 1997). Time spent together is an important relational currency (Baxter et al., 1991), but we also know that friendships can endure long separations. Compatability is an important element of friendship, but friendships can also weather some degree of tension and conflict.

Surprisingly, reciprocity is not a requirement for friendship in humans; it may even jeopardize friendship. Friendship seems to transcend an obligation to repay favors, loans, and other forms of help in kind, while less intimate relationships are based on balanced tit-for-tat exchanges (Clark \& Mills, 1979; Mills \& Clark, 1994; Lydon et al., 1997). Clark \& Mills (1979) propose that there are two discrete categories of social relationships, communal and exchange. In exchange relationships, benefits are given with the expectation 
that they will be repaid. In communal relationships, which characterize close kin and good friends, each party is principally concerned with the other's welfare and benefits directed to others do not create a specific obligation to reciprocate (Clark \& Mills, 1979). In fact, individuals in communal relationships seem to obscure their own contributions to joint tasks making precise accounting (and tit-for-tat reciprocity) impossible (Clark, 1984).

Readers should be aware that this description of the properties of friendship is based mainly on subjects in Western societies. It is not clear whether these are universal features of friendship. Nonetheless, these findings are useful for my purposes here because our use of the word to describe social relationships in nonhuman primates is based on a Western perspective on human friendships.

\section{What do primatologists mean when they use the ' $F$ '-word?}

I have not conducted a systematic survey of the use of the term 'friendship' in the primatological literature, but my impression is that the term was generally avoided until fairly recently. My keyword searches turned up several citations for the words friend and friendship in the last decade, but virtually none before that. Primatologists sometimes described nonaggressive interactions as friendly, but they did not often use the term friendship to characterize relationships between individuals. It is not clear whether this was due to a reluctance to use a term with such strongly anthropomorphic connotations or to researchers' perception that this was not an apt description of social relationships in primate groups. I suspect it was the former, it may have been the latter. However, this situation has now begun to change.

Researchers, struck by the prominence of close ties between certain pairs of adult males and females in savanna baboon groups, were among the first to make use of the term friendship in describing social relationships among nonhuman primates. These relationships were initially characterized as 'pair bonds' (Ransom, 1981), 'associations' (Altmann, 1980), 'special relationships' (Smuts, 1983a, b), and sometimes as 'friendships' (Strum, 1975, 1987). Although she was not the first to use the term friendship to refer to these kinds of special relationships between males and females, Barbara Smuts' book, Sex and friendship in baboons (1985), brought this term out of the closet. More recently, a number of other researchers have used the term 
friendship to describe close and exclusive male-female relationships that persist beyond the mating period in macaques (e.g. Manson, 1994; Maestripieri, 2000), chimpanzees (Hemelrijk et al., 1999), and other populations of baboons (Palombit et al., 1997).

Primatologists also use the term 'friendship' in a more general way to characterize close and affiliative social relationships, which may include same-sex partners. Tomasello \& Call (1997), use friendship as synonym for close affiliative bonds. Cords (1997) notes that "the terms 'friendship' or 'bond' usually imply affiliation in the form of extraordinary proximity or gooming or both". Chapais (1995) defines "any pair of individuals that maintain a mutually beneficial relationship" as friends. Similarly, Goodall (1986) defined friendly relationships in chimpanzees as those in which "affiliative behaviors outweigh aggressive ones, both in quantity and quality", and defines friends as dyads who have strong and enduring friendly relationships that are "characterized by two-way affiliative, supportive interactions" (italics in original). Colvin (1983), who studied social relationships among juvenile male rhesus macaques, concluded that some pairs of juvenile males established relationships that could be considered friendships, characterized by mutual preference, attraction, and high rates of affiliative interactions. Noë \& Sluijter (1995) describe friendships as relationships "characterized by higher than average frequencies of behaviors that imply tolerance and attachment, like close proximity, low aggression, tolerance at food resources, etc." (I invite readers to send me other examples of the use of the terms friend and friendship in studies of nonhuman primates).

\section{Can nonhuman primates be friends?}

Friendship in humans is defined by the kind of emotional bond that exists between individuals, not just by the kinds of things that they do together (Hinde, 1981). In contrast, definitions of friendship in nonhuman primates rely mainly on the frequency and patterning of their social interactions and we have limited access to their internal emotional states. This will make it extremely difficult, and very likely impossible, to compare the experience of friendship among humans and other primates.

Some of the features of human friendship, such as sympathy and understanding of the others' needs and desires, may exceed the cognitive capacities of some nonhuman primates. Monkeys seem to have a very limited theory of 
other's minds. They can predict what others will do, but they seem to have a limited understanding of others' perspectives, knowledge, and feelings (Cheney \& Seyfarth, 1990; Tomasello \& Call, 1997). Apes' understanding of others' minds may fall somewhere between monkeys and humans.

These things might mean that we should abandon the use of the term friendship in nonhuman primates, reserving the word friendship for humans and adopting some other, less anthropomorphic term for other species. This might be a good idea because it would prevent unproductive debates about whether friendships in human and nonhuman primates are the 'same'. I stipulate that they are not the same.

But before we dismiss the idea that nonhuman primates form friendships, I think that we need to consider the possiblity that there are some important ways in which these kinds of relationships are similar. After all, I suspect that most people would be comfortable describing human friendships as close social bonds, even though we might not be comfortable in describing close social bonds in nonhuman primates as friendships.

Thus, some of the features of friendship in human and close social bonds in nonhuman primates are similar, and can be quantified. Time is one of the main currencies of friendship in humans - friends spend time together (Hinde, 1981; Baxter et al., 1997). Although human friendships can endure long separations, no relationship can develop into friendship without some investment of time. This is a quantity that we can easily measure when we study nonhuman primates. In humans, support, particularly emotional support, is an important element of friendship. In nonhuman primates, there is limited evidence of emotional support in the form of consolation (de Waal \& Aureli, 1996), but more evidence of material support, such as coalitionary aid. Other attributes of human friendship, such as tolerance, compatability, loyalty, security and equality, may also be elements of close social bonds in nonhuman primates.

These similarities may reflect essential attributes of these relationships, and may give us important hints about their evolutionary history and adaptive value. If we take this view, then our next task to to think about how we can study these kinds of relationships in nonhuman primates, regardless of whether we call them friendships, close affilitive bonds, or special relationships. While psychologists can ask their subjects to list their friends, and describe attributes of their friendships on numerical scales, primatologists have to rely on external assessments of behavior to evaluate the nature of social relationships among our subjects. 


\section{Studying social relationships by observing social interactions}

"The study of social behavior is no substitute for the study of social relationships"

(Hinde, 1981).

Friendship is a particular kind of social relationship. Thus, to identify friendships, we must have some notion of how to assess the structure and quality of social relationships. In principle, social relationships can be conceptualized as the outcome of a contingent series of interactions between two individuals. A relationship between two individuals "can be described in terms of what they do together (the content of their interactions), how they do it (the qualifiers) and the relative frequency and patterning in time" (Hinde, 1983).

Primatologists routinely collect information about the content, quality, frequency, and patterning of interactions among individuals. There is broad consensus about the appropriate methodology for this kind of work, with a strong emphasis on the use of focal sampling (Altmann, 1974) to obtain systematic records of the sequence, patterning, duration, and rate of dyadic interactions.

\section{Content}

Although most primatologists construct detailed ethograms and code a long list of behaviors to record, analyses of social relationships are usually based on a very small subset of the elements of these ethograms. Grooming and proximity are the most common metrics used to gauge the quality of social relationships.

Proximity is a convenient thing to measure because associations are relatively frequent and long-lasting (Cords, 1997). This makes it possible to generate accurate information about spatial associations. However, it is not clear how data on proximity should be interpreted because spatial associations, even close proximity, don't require any active engagement by the two parties (Cords, 1997). Two animals may spend a lot of time together because both are simultaneously attracted toward a third party. This is a particularly thorny problem for untangling relationships among maternal kin (Chapais, 2001). Sisters may spend a lot of time in proximity because both are attracted toward their mother, not because they are attracted to 
one another. In Moremi, newborn infants play a pivotal role in some malefemale friendships (Palombit et al., 1997). If the infant dies or disappears, the males' attentiveness to his female friend is rapidly attenuated. High rates of association between males and females may simply reflect their common interest in the infant.

It makes sense that closeness would facilitate proximity, but to verify this intuition, we need to show that proximity is consistently associated with other kinds of positive or affiliative behavior (Cords, 1997). There is some evidence that proximity is correlated with higher frequencies of affiliative interactions and negatively related to aggression. However, these correlations may be the product of other variables (such as kinship or rank). Thus, we need more direct evidence that proximity is useful as an independent measure of the quality of social bonds.

Grooming may provide a more useful index of the nature of social relationships. Nonhuman primates are thought to use grooming to cultivate and maintain social bonds (Dunbar, 1991). The logic underlying this idea relies on several factors. First, grooming is the most common form of affiliative behavior among primates, occupying up to $20 \%$ of daily time budgets (Dunbar, 1991). Second, females seem to spend more time grooming than is necessary to satisfy simple hygienic needs. The proportion of time spent grooming generally increases with group size among Old World monkeys (Dunbar, 1988, 1991), suggesting that the hygienic functions of grooming have been superceded by social functions in these species. Third, female monkeys typically groom other females selectively, limiting grooming to a small subset of potential partners (Cheney, 1992; Henzi et al., 1997; Silk et al., 1999).

However, there are also some reasons to be cautious about accepting the idea that grooming provides a good measure of the quality of social bonds. First, not all nonhuman primates groom. For example, squirrel monkeys and muriquis rarely groom, but some dyads do form close social bonds (Boinski, 1994; Strier, 1992; Strier et al., this volume). Dunbar (1991) concluded that hygiene, not relationship management, is the primary function of grooming in New World monkeys.

Second, there is little direct evidence that grooming is used to cultivate valuable social bonds (Cords, 1997). Observations of positive correlations between rates of grooming and other forms of affiliative behavior, such as support (Seyfarth, 1976, 1980; Cheney \& Seyfarth, 1990; Hemelrijk, 
1990a; Silk, 1992; O’Brien, 1993; Mitani et al., 2000), food sharing (de Waal, 1997a; Mitani et al., 2000), and tolerance at feeding sites (Libet, 1994) support the idea that grooming is used to maintain valuable social bonds. However, it is always problematic to infer causal relationships from correlational data. If grooming and coalitionary support are beneficial to the recipients, kin selection could produce high rates of both grooming and coalitionary support among close kin. Thus, we must be careful to exclude the possibility that an observed correlation between grooming and support is actually a spurious effect of kinship (Hemelrijk \& Ek, 1991).

Third, not all grooming may serve the same function. Barrett and her colleagues (Barrett et al., 1999; Barrett \& Henzi, this volume) argue that female baboons use grooming as a commidity which they exchange for itself or for other resources, such as acess to newborn infants (see also Muroyama, 1984; Altmann, 1980). There is also evidence that grooming may be used to enhance strategic objectives such as access to food (Stammbach, 1978; de Waal, 1989) and inhibiting aggression (Fairbanks, 1980; Silk, 1982). In these situations, grooming may represent a means to an end, not an investment in an enduring relationship.

The behavioral dimensions of close social relationships have not been fully investigated. It is possible that there are other informative indicators of the quality of females' social relationships besides grooming and proximity. Cords (1997) suggests, for example, that 'vocal exchanges ... might be more satisfactory and more general indicators of social bonds among primates than measures such as grooming and proximity.' Hohmann \& Fruth (2000) suggest that genital contacts may provide useful information about the quality of social relationships among female bonobos. Other behaviors, such as embraces, sitting in contact, or greetings, might also provide useful cues about the quality of relationships, particularly in species in which social grooming is uncommon or absent altogether. However, there are certain practical considerations that constrain analytic options. Most importantly, relatively few social behaviors occur with sufficient frequency to sustain analyses at the dyadic level. Thus, researchers studying female baboons may be able to characterize patterns of grooming and supplants fairly fully, but data on other forms of social interactions that are potentially revealing components of social relationships, such as contact aggression, groom presents, embraces, mounting, muzzling, and coalitionary support, are often scant. 


\section{Frequency}

Measures of the strength of social bonds are usually based on the frequency of certain types of interactions between two individuals. In some cases, the observed distribution of certain kinds of interactions produces a 'natural' dichotomy. For example, Noë \& Sluijter (1995) examined the distribution of coalitions among adult male baboons, to determine whether "the higher values represent the extreme values in a continuous distribution or the exceptional pairs in a discontinuous distribution. In the latter case, the use of the term alliance for these special relationships would be warranted." They found more pairs than expected with very low frequences as well as very high frequencies, so they were able to categorize certain pairs of males as allies.

In other cases, interactions are distributed more uniformly across partners, making it much harder to draw categorical distinctions between dyads. In these cases, researchers have adopted a variety of procedures for classifying relationships. For example, Aureli et al. (1989) categorized social bonds as good, bad, weak, or unresolved. Good relationships were those in which the frequency of affiiation exceeded the group mean, while bad relationships were those in which the rate of affliation fell below the group mean and aggression exceeded the mean for the group. In Colvin's (1983) study of juvenile male rhesus macaques, dyads that spent more than $15 \%$ of their total proximity time together were said to have 'strong' relationships. Even though analyses based upon these criteria generate statistically significant patterns, the criteria are arbitrary, and they don't necessarily reflect the underlying distribution of the data.

Although it seems reasonable to think that the frequency of interactions would be a good measure of the strength of social bonds, this may not always be the case. Goodall (1986) argues that "When two individuals interact very little, it can mean either that their relationship is hostile and one avoids the other, or that they are very relaxed and tolerant of each other and have no need to interact frequently." (p. 176). In Amboseli, females did not often intervene in conflicts among other adult females. But when the dominance hierarchy was disrupted, coalitions among adult females had an important effect on the eventual outcome of rank challenges (Samuels et al., 1987). Similarly, female bonnet macaques showed relatively weak biases in favor of kin when they were grooming, but received coalitionary support only from close kin (Silk, 1982). 
In most studies of friendship, researchers rely on the frequency of interactions and associations to identify friends. For example, Smuts (1985) found that anestrus females typically groomed and associated with one or two adult males much more often than with other adult males. Such highly selective patterns of association and interaction were very unlikely to arise by chance. Like Smuts (1985), Palombit et al. (1997) computed a composite proximity score for each male female dyad. For most females, proximity scores to males were not continuously distributed. Scores for one or two males were clearly separated from scores for other males, and these males were designated as friends. Manson (1994) relied on a similar procedure to describe male-female friendships in rhesus macaques.

In other cases, the frequency of interactions within dyads serves as a proxy for the quality of social bonds. For example, In a paper entitled, 'Friendship' for fitness in chimpanzees, Hemelrijk et al. (1999) computed the frequency of 'social services' (grooming, support, and food sharing) performed by males on behalf of females and vice versa. Despite the title, they did not attempt to categorize the quality of relationships within particular dyads, and did not identify particular dyads as friends.

\section{Quality}

Qualitative assessments of social interactions seem likely to provide revealing information about the nature of social relationships, but methods for evaluating the quality of social interactions are quite limited. Saunders (1988) devised a system for scoring the effort and care devoted to grooming. Other researchers monitor time spent at different distances, weighing time spent in close proximity more heavily than time spent at greater distances (e.g. Perry, 1996). It is not uncommon to score the intensity of agonistic interactions, differentiating between threats, contact aggression, and escalated attacks.

Primatologists have recently begun to explore a new method for assessing the quality of social bonds. Rates of self-directed behaviors (scratching, selfgrooming, body shaking and yawning) are elevated when monkeys are under stress in naturalistic situations (reviewed in Castles et al., 1999). For example, after conflicts, rates of self-directed behavior are elevated over baseline levels, but fall to baseline levels after former opponents reconcile (Aureli et al., 1989; Smucny et al., 1997; Aureli, 1997; Castles \& Whiten, 1998; Das et al., 1998). 
These results suggest that rates of self-directed behavior may provide information about the quality of social bonds between group members. Thus, Castles et al. (1999) compared the rates of self-directed behavior by females when their nearest neighbors were higher-ranking and lower-ranking than themselves. On average, rates of self-directed behaviors were $40 \%$ higher when the nearest neighbor was dominant than when the nearest neighbor was subordinate. These results suggest that self-directed behavior may provide a useful probe for assessing relationship quality. However, it is not clear whether this measure is valid across taxa. All of the studies cited above were conducted on macaques and baboons. In the only study conducted on New World priamtes, Manson \& Perry (2000) found that rates of selfdirected behaviors do not rise after conflicts among white-faced capuchins, and rates of self-directed behaviors are positively correlated with time spent in proximity. This suggests that (a) self-directed behaviors do not have the same meaning in all primate taxa, or (b) the nature of stressful situations differs across species.

Another way to guage the quality of social relationships may be to monitor what animals do when they are together. For example, tolerance of close proximity during feeding (co-feeding) may be a useful measure of the quality of social bonds (de Waal, 1989; Cords \& Thurnheer, 1993; Libet, 1994).

\section{Patterning}

Primatologists regularly assess a number of characteristics of the patterning of social interactions within groups. Thus, we assess the extent of nepotism in social interactions within groups (e.g. Silk et al., 1999) and across species (Cheney, 1992). We also measure the extent of egalitarianism by evaluating how often subordinates challenge dominants (e.g. Thierry, 1986, 1990). Reciprocity and diversity are two aspects of the patterning of social interactions that seem particularly relevant to friendship.

A number of workers contend that reciprocity is an important component of friendship (Colvin, 1983; Goodall, 1986; Chapais, 1995; Maestripieri, 2000). In this context, reciprocity refers to the balance of behavioral acts given and received, not to the mechanisms that produce this patterning which play an important role in game theoretical treatments of reciprocal altruism (Axelrod \& Hamilton, 1981). The extent of reciprocity within dyads seems to vary across species. In macaques and vervets grooming is typically 
directed up the hierarchy (Fairbanks, 1980; Seyfarth, 1980; Silk, 1982; Chapais, 1983), but in female-bonded wedge-capped capuchins grooming is directed down the hierarchy (O'Brien, 1993; Parr et al., 1997), and in whitefaced capuchins grooming is evenly balanced within the majority of dyads (Manson et al., 1999). Among free-ranging baboons, the pattern is equally variable. In some baboon groups, grooming is directed up the hierarchy (Sambrook et al., 1995), but in other groups grooming is directed mainly down the hierarchy (Saunders, 1988; Altmann et al., 1998), and in some groups grooming is highly reciprocal producing no bias with respect to rank (Silk et al., 1999; Barrett et al., 1999). Female baboons, Japanese macaques, and blue monkeys often alternate roles within bouts, closely matching the time spent grooming and being groomed (Muroyama, 1991; Rowell et al., 1991; Saunders, 1988; Barrett et al., 1999; Cords, this volume).

A variety of methods have been used to assess the degree of reciprocity within dyads. One way is to calculate the proportion of interactions initiated by one member of the dyad (e.g. de Waal \& Luttrell, 1988; Silk, 1992). Measures like this are problematic because skews in small samples are likely to arise by chance. One way to avoid this problem is to compute the Binomial probability of obtaining the observed distribution of acts given and received if interactions were actually evenly balanced within the dyad (Boyd \& Silk, in prep.; see Silk et al., 1999). Matrix correlation methods (Hemelrijk, 1990a, b; de Vries, 1993) are useful for assessing the extent of reciprocity across dyads within groups.

Friendship seems to require some degree of discrimination and selectivity; relationships must be differentiated. In many groups, not all individuals groom or interact with each other. For example, female baboons in Moremi groomed on average eight of the other 18 adult females in their group, and half of these females devoted the majority of their grooming to just one other female (Silk et al., 1999). Primatologists have used the Shannon-Weaver diversity index to assess how evenly individuals distribute grooming and other interactions across potential partners (Cheney, 1992; Henzi et al., 1997; Manson et al., 1999; Silk et al., 1999; di Bittetti, 2000). Di Bitetti (2000) has shown that this index is sensitive to sampling effort and must be corrected for observation time to avoid biased results. 


\section{Picking friends out of the crowd}

The method that Smuts (1985) developed for identifying male-female friendships among baboons has the great virtue of being precise and unambiguous. It is also has the virtue of being empirically grounded, as it reflects the underlying distribution of the data. This method won't substitute for a definition of friendship because it doesn't address the nature of the relationship among friends.

It seems to me that social relationships must have certain qualities in order for it to make sense for us to describe them as friendships. I suggest that friendship should be reserved for relationships among nonkin that are characterized by frequent participation in affiliative interactions (often, but not necessarily, including grooming); involvement in coalitionary aggression, particularly in defense of the partner; high rates of association; mutual responsibility for maintaining proximity; high degrees of reciprocity in directional, nonaggressive activities such as grooming and food sharing; continuity across time and context; high degrees of tolerance (co-feeding), loyalty, and compatability; and low degrees of stress when together.

This is a long way from an operational definition of friendship. For example, how often must two females groom to be considered friends? How well-balanced must exchanges of food be to be considered reciprocal? How long must relationships persist to qualify as friendships? How can we quantify tolerance and compatibility? We need to work on methods that enable us to describe these qualities quantitatively and generate empiricallygrounded criteria to distinguish friends from others. It seems very unlikely that the same quantitative criteria will work for all species, but the same kinds of methods might work to generate species-specific criteria.

This definition is meant to exclude certain kinds of relationships. Thus, females who groom mothers of newborns to gain access to their infants, but do not groom them much at other times, are not friends because their relationships are asymmetric (mothers never initiate the contacts) and they don't persist in time (mothers are only attractive when their infants are young). Male baboons regularly form alliances with particular partners, but most pairs of allies do not necessarily spend much time together (Collins, 1981; Noë \& Sluijter, 1995), are not inhibited about fighting with one another or forming coalitions against one another (Noë \& Sluijter, 1995). Thus, allies are not necessarily friends. 
High rates of grooming and association between males and estrous females do not constitute friendships if the association ends when females become unreceptive. Similarly, when chimpanzees swap meat for sex (Stanford et al., 1994; Stanford, 1996) or trade grooming for food (de Waal, 1997), these short-term exchanges should not be equated with friendship.

This definition is also meant to exclude relationships among relatives. This may be a controversial proposition. After all, relationships among close kin and unrelated friends are often quite similar, displaying high rates of affiliation, reciprocity, and support. However, I suspect that the proximate mechanisms involved in the formation of social relationships among kin and nonkin will prove to be quite different. As the saying goes, "you can pick your friends, but you can't pick your relatives". One consequence of this is that relationships with close kin may turn out to be much less variable than relationships among unrelated individuals, only some of whom become friends. Another reason to differentiate between close relationships among kin and nonkin is that the evolutionary forces shaping these kinds of relationships among kin and nonkin are likely to differ, as I will discuss below.

I am uncertain whether relationships in which exchanges are consistently asymmetric should qualify as friendships. Thus, when a bonnet macaque male grooms a high ranking male who consistently supports him (Silk, 1992), or when a female baboon grooms a female in order to get a chance to touch her infant (Barrett \& Henzi, this volume), they may be exchanging services on a contingent basis, not forming a friendship. I suggest that asymmetric relationships should only qualify as friendships if they meet the additional criteria mentioned above, such as joint responsibility for maintaining proximity; long-term continuity; tolerance, loyalty, and little stress when together.

Paradoxically, the best studied case of friendship, the distinctive and exclusive relationships among male and female baboons, may not satisfy my definition. These relationships may be mutually beneficial, as females obtain protection for themselves and their offspring while males may gain future mating advantages (Smuts, 1985), access to infants that they can use in triadic interactions with other males (Smuts, 1985) or safeguard their own infants' safety (Palombit et al., 1997). But these relationships are not reciprocal - female baboons groom their male friends much more than their male friends groom them, and females are principally responsible for maintaining proximity to their male friends (Smuts, 1985; Palombit et al., 
1997). Moreover, not all of these relationships are enduring. In Moremi, the male-female associations that Palombit and his colleagues studied persisted only as long as the infant survived (Palombit et al., 1997). Perhaps we should find another label for these kinds of relationships, or return to calling them 'special relationships'.

\section{Evolutionary forces shaping friendship}

In nonhuman primates, we generally assume that kin selection (Hamilton, 1964) and reciprocal altruism (Trivers, 1971; Axelrod \& Hamilton, 1981) shape the distribution of altruistic behaviors. High rates of grooming, support, food sharing, and proximity among kin are usually thought to be the product of kin selection (Silk, 2001, in press; but see Chapais, 2001). If friends are, by definition, nonrelatives, then friendship would have to be the product of reciprocal altruism. Most of the discussion of friendship in the primatological literature is consistent with this hypothesis, and there is reasonably good evidence that nonhuman primates tend to reciprocate favors in kind or trade one kind of help for another (Silk, in press). Most of this evidence is correlational. For example, female vervets are most likely to support unrelated females who groom them most often (Cheney \& Seyfarth, 1990).

Reciprocal altruism requires a contingent exchange of benefits. That is, one party will not provide a benefit to the other unless they have previously received a benefit themselves. Experimental studies of reciprocity in nonhuman primates suggest that such immediate contingencies do facilitate altruistic behavior (de Waal, 1997a, b, 2000). Vervets and macaques are more likely to support unrelated females who have recently groomed them (Seyfarth \& Cheney, 1984; Hemelrijk, 1994). Chimpanzees are more likely to share food with animals who have recently groomed them (de Waal, 1997a), and capuchins are more likely to share food with others who have just shared their own food with them (de Waal, 1997b, 2000).

We do not know how nonhuman primates track these contingencies and maintain reciprocal relationships. Barrett et al. (1999; Barrett \& Henzi, this volume) have argued that baboons, which often alternate the direction of grooming within bouts, do not have the cognitive ability to keep track of their accounts over long periods, and must match their partner's contributions in real time. Thus, they parse grooming into short episodes and alternate roles frequently. However, there is some evidence that chimpanzees balance 
their accounts over longer periods. De Waal (1997a) found that in pairs of chimpanzees that rarely groomed, sharing was strongly contingent on recent grooming, while for pairs that groomed at higher rates, recent grooming had a smaller impact on sharing (de Waal, 1997a). These data suggest that close ties among chimpanzees preclude the need for reciprocity, or that chimpanzees can keep track of exchanges over longer periods and require immediate payment only from those who they don't regularly interact with. Thus, present evidence suggests that reciprocal altruism provides a plausible, though not fully tested, mechanism for the evolution of friendship in nonhuman primates.

Evolutionary analyses of human friendship are relatively limited and unsatisfying. Evolutionary biologists writing about human friendship have argued that human friendships are product of kin selection or reciprocal altruism. Alexander (1979) relies on the former explanation. He argues that humans have lived in conditions like those of modern foragers for most of their evolutionary history. In these societies, people interact mainly with close relatives, and have no need to distinguish between kin and nonkin or between reciprocators and nonreciprocators. Thus, we continue to treat close associates like kin because our ancestors had few opportunities to interact with strangers and had little need to discriminate between kin and nonkin. Our modern capacity for friendship is a product of our history of nepotism.

I find this explanation unconvincing for several reasons. First, even in small foraging societies, people do come into contact with strangers and with nonrelatives. They make choices about who to marry, who to live with, and who to establish trading relationships with. The social arrangements that we observe are the product of these choices, not simply the result of constraints that make alternatives impossible. Second, even in traditional foraging communities, not all potential partners are equally valuable in adaptive terms. Even in foraging societies, people should be expected to discriminate between close kin and distant kin, between relatives with high reproductive value and low reproductive value, and between reliable and unreliable reciprocators. Living among close kin does not eliminate the need for such discrimination, it just makes the discrimination more difficult. Finally, I am uncomfortable with explanations that assume that humans are less flexible in their behavior than monkeys. In macaque groups, the average degree of relatedness among females is relatively high. Nonetheless, females 
clearly discriminate among potential partners, interacting selectively with close kin and reciprocating partners.

Others have argued that friendship is the product of reciprocal altruism. For example, Hewlett (2001) writes, "Friendship, alliances, and cooperatives are just a few examples of reciprocal altruism and are especially common in stratified societies." Kenrick \& Trost (2000) argue that friendship was favored by natural selection because it provides a basis for trade and alliance formation. This is a logical explanation of friendship in humans, but it doesn't provide a good fit to some of the the data collected by social psychologists who consistently report that friendship does not require, and may actually be damaged by, tit-for-tat reciprocity.

It is possible that our folk notions about friendship, and the results of social psychology studies, are based on false premises. While subjects consistently report that they do not monitor benefits given and received from their friends and associates, introspection may be misleading. People may suppress conscious calculations of reciprocity, or may simply be unwilling to admit that they keep mental accounts. It is also possible that it is best to ignore short-term asymettries in benefits given and received. Theoretical investigations of reciprocity suggest that tolerance of short-term imbalances may preserve valuable long-term reciprocal relationships (Bendor, 1993; Boerlijst et al., 1997). However, a willingness to overlook occasional lapses must be coupled with a sensitivity to persistent exploitation. The tendency to deny or suppress calculations of reciprocity seems likely to facilitate such exploitation. All we can say at this point is that human friendships seem to present a puzzle for evolutionary biologists.

\section{Adaptive consequences of friendship}

"From an evolutionary perspective, the fact that primates form special friendships or bonds would be of little interest if these relationships did not confer on the participants some advantage related to survival and reproduction" (Cords, 1997, p. 29).

A growing body of evidence indicates that close social bonds, and friendship, have adaptive value. Some of the behaviors that we use to characterize friendships are associated with beneficial effects on the recipient. Thus, monkeys who are being groomed experience reduced heart rates (Boccia et al., 1989; Aureli \& Smucny, 2000). In some species, dyads with close 
social relationships reconcile at higher rates than others (Cords \& Aureli, 2000). Reconciliation produces more rapid reduction in the rates of selfdirected behavior, and is thus likely to be associated with more rapid alleviation of stress after conflicts (Aureli et al., 1989; Das et al., 1998; Castles \& Whiten, 1998). The extent of social integration among male baboons is negatively correlated with basal cortisol levels (Sapolsky et al., 1997). Among humans, friendship seems to have similar effects. Social support, which is defined as the perception of caring and understanding from the members of the social network, buffers minor chronic stress (reviewed by Taylor et al., 2000).

It is more difficult to translate these proximate effects into real fitness advantages. In humans, chronic stress is associated with long-term health consequences, and social support therefore enhances mental and physical health (House et al., 1988). In nonhuman primates, such links are more tenuous. We can make a strong case that nepotism has reproductive consequences (Cheney et al., 1986; Silk, 2000, in press), but it is more difficult to document reproductive advantages associated with close social relationships among nonrelatives.

Male-female friendships among baboons may enhance males' mating prospects (Smuts, 1985) or protect infants from infanticidal attacks (Palombit et al., 1997). Among chimpanzees, the exchange of social services among males and females apparently does not translate directly into reproductive advantages for males (Hemelrijk et al., 1999). In Japanese and rhesus macaques, friendship actually inhibits sexual behavior (Manson, 1995). Alliances in consort takeovers among baboons enhance males' reproductive opportunities by providing access to receptive females (Packer, 1977; Bercovich, 1988; Noë \& Sluijter, 1990), so relationships among alliance partners may have adaptive value (Cheney et al., 1997). However, it is not clear that these alliances meet the criteria for friendships - most pairs of allies don't spend much time together or engage in high levels of affiliative behavior.

The multi-dimensional relationships of male chimpanzees may provide a better example of the fitness-enhancing effects of friendship. Males have well-differentiated grooming relationships, and they groom reciprocally (Watts, 2000, this volume). They tend to groom the same males that they support in agonistic contests and share food with (Mitani et al., 2000; Mitani $\&$ Watts, 2001). Males also cooperatively mate guard and share matings with 
their close associates (Watts, 1998). Since close associates are usually not maternal kin (Mitani et al., 2000), these close social bonds among males may not be the product of kin selection.

At this point, we simply don't have many other good examples of fitness benefits derived from friendship. Of course, this is not surprising since we have just begun to recognize that these kinds of relationships exist and to focus on the nature of relationships among unrelated individuals.

\section{Conclusion}

I think that primatologists should continue to explore the possibility that nonhuman primates form friendships. This means that we need to pay more attention to methodological details, such as how we should interpret information about the content, frequency, quality, and patterning of social interactions. Although few of us take up primatology because we are fascinated by methodological issues, we will make little progress if we don't attend to this problem. The methods that we have developed are useful for studying social behavior, but not very useful for analyzing social relationships.

We also need to agree on the defining features of friendship. I am sure that many readers will quibble with the description of friendship that I have provided here; anyone who wishes to amend this description is welcome to do so, but eventually we must reach a consensus about the features that define friendship among nonhuman primates. We need to debate this question and reach some agreement about what we mean by friendship in nonhuman primates.

I also think that we need more information about the natural history of friendship. We know a lot about the nature of social relationships among kin, but much less about the structure of relationships among nonkin. Do all (any) nonhuman primates have friendships? How many friends do individuals have? How are friends chosen and friendships cultivated and maintained? Is the size of nonkin networks constrained by ecological factors, demography, residence patterns, age, sex, or reproductive status? This list could be continued, but the general point is clear. Our knowledge of friendship in nature is still quite limited.

These are the kinds of data that we need to have to understand how natural selection has shaped the evolution of friendship in nonhuman primates. We 
may discover that friendship plays little role in the everyday lives of other primates. If so, we will wonder why and how friendship has become a more important part of the lives of modern humans than it has in the lives other primates. We may discover that friendship is a crucial element of the adaptive strategies of other primates. This would also shape our ideas about the evolutionary history of friendship among humans. Whatever the answer, the questions are worth pursuing.

\section{References}

Alexander, R.D. (1979). Natural selection and social exchange. - In: Social exchange in developing relationships (R.L. Burgess \& T.L. Huston, eds). Academic Press, New York, p. 197-221.

Altmann, J. (1974). Observational study of behavior: sampling methods. - Behaviour 49, p. 227-267.

- - (1980). Baboon mothers and infants. - Harvard University Press, Cambridge.

- - J., Myles, B. \& Combes, S. (1998). Grooming relationships in a primate group: social cohesion or currying favors? - Poster presented at the meetings of the American Primatological Society.

Aureli, F. (1997). Post-conflict anxiety in nonhuman primates: the mediating role of emotion in conflict resolution. - Aggr. Behav. 23, p. 315-328.

— —, van Schaik C.P. \& van Hooff, J.A.R.A.M. (1989). Functional aspects of reconciliation among captive long-tailed macaques (Macaca fasicularis). - Am. J. Primatol. 19, p. $39-51$

- — \& Smucny, D.A. (2000). The role of emotion in conflict and conflict resolution. — In: Natural conflict resolution (F. Aureli \& F.B.M. de Waal, eds). University of California Press, Berkeley CA, p. 199-224.

Axelrod, R. \& Hamilton, W.D. (1981). The evolution of cooperation. - Science 211, p. 13901396.

— —, — —, Weingrill, T., Lycett, J.E. \& Hill, R.A. (1999). Market forces predict grooming reciprocity in female babons. - Proc. Roy. Soc. 266, p. 665-670.

Baxter, L.A., Mazanec, M., Nicholson, J. Pittman, G., Smith, K. \& West, L. (1997). Everyday loyalties and betrayal in personal relationships. - J. Soc. Pers. Rels. 14, p. 655-678.

Bendor, J. (1993). Uncertainty and the evolution of cooperation. - J. Conflict Resol. 37, p. 709-734.

Bercovich, F.B. (1988). Coalitions, cooperation, and reproductive tactics among adult male baboons. - Anim. Behav. 36, p. 1198-1209.

Boccia, M.L., Reite, M. \& Laudenslager, M.L. (1989). The physiology of grooming in a pigtail macaque. - Physiol. Behav. 45, p. 667-670.

Boerlijst, M.C., Nowak, M.A. \& Sigmund, K. (1997). The logic of contrition. - J. Theor. Biol. 185, p. 281-293.

Boinski, S. (1994). Affiliation patterns among male Costa Rican squirrel monkeys. Behaviour 130, p. 191-209. 
Castles, D.L. \& Whiten, A. (1998). Post-conflict behavior of wild olive baboons. I. Reconciliation, redirection, and consolation. - Ethology 104, p. 126-147.

— — - — — \& Aureli, F. (1999). Social anxiety, relationships and self-directed behaviour among wild female baboons. - Anim. Behav. 58, p. 1207-1215.

Chapais, B. (1983). Dominance, relatedness, and the structure of female relationships in rhesus monkeys. - In: Primate social relationships: an integrated approach (R.A. Hinde, ed.). Blackwell, Oxford, p. 208-217.

- - (1995). Alliances as a means of competition in primates: evolutionary, developmental, and cognitive aspects. - Yrbk. Phys. Anthropol. 38, p. 115-136.

- - (2001). Primate nepotism: what is the explanatory value of kin selection? - Int. J. Primatol. 22, p. 203-229.

Cheney, D.L. (1992). Intragroup cohesion and intergroup hostility: the relation between grooming distributions and intergroup competition among female primates. - Behav. Ecol. 3, p. 334-345.

— — \& Seyfarth, R.M. (1990). How monkeys see the world. — University of Chicago Press, Chicago.

— — - — — \& Smuts, B. (1986). Social relationships and social cognition in nonhuman primates. - Science 234, p. 1361-1366.

Clark, M.S. (1984). Record keeping in two types of relationships. - J. Pers. Soc. Psychol. 47, p. $549-557$.

— — \& Mills, J. (1979). Interpersonal attraction in exchange and communal relationships. — J. Pers. Soc. Pyschol. 37, p. 12-24.

Collins, D.A. (1981). Social behaviour and patterns of mating among adult yellow baboons (Papio c. cynocephalus L. 1766). - PhD thesis, Univ. of Edinburgh.

Colvin, J. (1983). Description of sibling and peer relationships among immature male rhesus monkeys. - In: Primate social relationships: an integrated approach. Blackwell Scientific, Oxford, p. 20-27.

Cords, M. (1997). Friendship, alliances, reciprocity and repair. — In: Machiavellian intelligence II (A. Whiten \& R.W. Byrne, eds). Cambridge University Press, Cambridge, p. 24-49.

— — \& Aureli, F. (2000). Reconciliation and relationship qualities.— In: Natural conflict resolution (F. Aureli \& F.B.M. de Waal, eds). University of California Press, Berkeley, CA, p. 177-198.

— — \& Thurnheer, S. (1993). Reconciliation with valuable partners by long-tailed macaques. - Ethology 93, p. 315-325.

Das, M., Penke, Zs \& van Hooff, J.A.R.A.M. (1998). Postconflict affiliation and stress-related behavior of long-tailed macaque aggressors. - Intl. J. Primatol. 19, p. 53-71.

Davis, K.E. \& Todd, M.J. (1985). Assessing friendship: prototypes, pardigm cases and relationship description. - In: Understanding personal relationships: an interdisciplinary approach (S. Duck \& D. Perlman, eds). Sage Publications, London, p. 17-38.

DiBitetti, M.S. (2000). The distribution of grooming among female primates: testing hypotheses with the Shannon-Wiener diversity index. - Behaviour 137, p. 1517-1540.

Dunbar, R.I.M. (1988). Primate social systems. - Croom Helm, London.

- _ (1991). Functional significance of social grooming in primates. - Folia primatol. 57, p. 121-131.

Fairbanks, L. (1980). Relationships among adult females in captive vervet monkeys: testing a model of rank-related attractiveness. - Anim. Behav. 28, p. 853-859. 
Goodall, J. (1986). The chimpanzees of Gombe: patterns of behavior. — The Belknap Press, Cambridge, MA.

Hemelrijk, C.K. (1990a). Models of, and tests for, reciprocity, unidirectionality and other social interaction patterns at a group level. - Anim. Behav. 39, p. 1013-1029.

- - (1990b). A matrix partial correlation test used in investigations of reciprocity and other social interaction patterns at a group level. - J. theor. Biol. 143, p. 405-420.

— - (1994). Support for being groomed in long-tailed macaques, Macaca fasicularis. — Anim. Behav. 48, p. 479-481.

— — \& Ek, A. (1991). Reciprocity and interchange of grooming and 'support' in captive chimpanzees. - Anim. Behav. 41, p. 923-935.

— —, Meier, C. \& Martin, R.D. (1999). 'Friendship' for fitness in chimpanzees? — Anim. Behav. 58, p. 1223-1229.

Henzi, S.P., Lycett, J.E. \& Weingrill, T. (1997). Cohort size and the allocation of social effort by female mountain baboons. - Anim. Behav. 54, p. 1235-1243.

Hewlett, B. (2001). Neoevolutionary approaches to human kinship. — In: New directions in anthropological kinship (L. Stone, ed.). Rowman and Littlefield, Lanham, MD, p. 93108.

Hinde, R.A. (1981). The bases of a science of interpersonal relationships. — In: Personal relationships. 1: Study of personal relationships(S. Duck \& R. Gilmour, eds). Academic Press, NY, p. 1-22.

— — (ed.) (1983). Primate social relationships: an integrated approach. — Blackwell Scientific Publications, Oxford.

Hohmann, G. \& Fruth, B. (2000). Use and function of genital contacts among female bonobos. - Anim. Behav. 60, p. 107-120.

House, J.S., Landis, K.R. \& Umberson, D. (1988). Social relationships and health. — Science 241, p. 540-545.

Hrdy, S.B. (1976). The care and exploitation of nonhuman primate infants by conspecifics other than the mother. - In: Advances in the study of behavior, vol. 6 (J. Rosenblatt, R. Hinde, E. Shaw \& C. Beer, eds). Academic Press, New York, p. 101-158.

Kenrick, D.T. \& Trost, M.R. (2000). An evolutionary perspective on human relationships. In: The social psychology of personal relationships (W. Ickes \& S. Duck, eds). John Wiley \& Sons, New York, p. 9-35.

Libet, M.L. (1994). Bonding and tolerance among unrelated adult females of disparate rank in a large captive group of rhesus monkeys (Macaca mulatta). - $\mathrm{PhD}$ thesis, Univ. of California, Davis.

Lydon, J.E., Jamieson, D.W. \& Holmes, J.G. (1997). The meaning of social interactions in the transition from acquaintanceship to friendship. - J. Pers. Soc. Psych. 73, p. 536-548.

Maestripieri, D. (1994). Social structure, infant handling, and mother styles in group-living Old World monkeys. - Int. J. Primatol. 15, p. 531-553.

- - (2000). Determinants of affiliative interactions between adult males and lactating females in pigtail macaques (Macaca nemestrina nemestrina). — Ethology 106, p. 425439.

Manson, J.H. (1994). Mating patterns, mate choice, and birth season heterosexual relationships in free-ranging rhesus macaques. - Primates 34, p. 417-433.

_ — \& Perry, S. (2000). Correlates of self-directed behaviour in wild white-faced capuchins. —Ethology 106, p. 301-317. 
— —, Rose, L.M., Perry, S. \& Gros-Louis, J. (1999). Dynamics of female-female relationships in wild Cebus capucinus: data from two Costa Rican sites. - Int. J. Primatol. 20, p. 679-706.

Mills, J. \& Clark, M.S. (1994). Communal and exchange relationships: controversies and research. - In: T heoretical frameworks for personal relationships (R. Erber, R. Gilmour, eds). Lawrence Erlbaum Assoc, Hillsdale, NJ, p. 29-42.

Mitani, J.C., Merriwether D.A. \& Zhang, C. (2000). Male affiliation, cooperation and kinship in wild chimpanzees. - Anim. Behav. 59, p. 885-893.

— — \& Watts, D.P. (2001). Why do chimpanzees hunt and share meat? - Anim. Behav. 61, p. $915-924$.

Muroyama, Y. (1991). Mutual reciprocity of grooming in female Japanese macaques (Macaca fuscata). - Behaviour 119, p. 161-170.

- - (1994). Exchange of grooming for allomothering in female patas monkeys. Behaviour 128, p. 103-119.

Noë, R. \& Sluijter, A.A. (1990). Reproductive tactics of male savanna baboons. - Behaviour 113, p. 117-170.

— — \& — — (1995). Which adult male savanna baboons form coalitions? — Int. J. Primatol. 16, p. 77-105.

O’Brien, T. (1991). Allogrooming behavior among adult female wedge-capped capuchins. Anim. Behav. 46, p. 499-510.

— — \& Robinson, J.G. (1991). Allomaternal care by female wedge-capped capuchin monkeys: effects of age, rank, and relatedness. - Behaviour 119, p. 30-50.

Parr, L.A., Matheson, M.D., Bernstein, I.S. \& de Waal, F.B.M. (1997). Grooming down the hierarchy: allogrooming in captive brown capuchin monkeys, Cebus apella. - Anim. Behav. 54, p. 361-367.

Paul, A. (1999). The socioecology of infant handling in primates: is the current model convincing? - Primates 40, p. 33-46.

Packer, C. (1977). Reciprocal altruism in Papio anubis. - Nature 265, p. 441-443.

Palombit, R.A., Seyfarth, R.M. \& Cheney, D.L. (1997). The adaptive value of 'friendships' to female babons: experimental and observational evidence. - Anim. Behav. 54, p. 599614.

Perry, S. (1996). Female-female social relationships in wild white-faced capuchin monkeys (Cebus capucinus). - Amer. J. Primatol. 40, p. 167-182.

Ransom, T.W. (1981). Beach troop of the Gombe. - Bucknell University Press, Lewisburg, NJ.

Reisman, J.M. (1981). Adult friendships. - In: Personal relationships. 2: Developing personal relationships (S. Duck \& R. Gilmour, eds). Academic Press, NY, p. 205-230.

Rowell, T.E., Hinde, R.A. \& Spencer-Booth, Y. (1964). 'Aunt'-infant interactions in captive rhesus monkeys. - Anim. Behav. 12, p. 219-226.

— - Wilson, C. \& Cords, M. (1991). Reciprocity and partner preference in grooming of female blue monkeys. - Int. J. Primatol. 12, p. 319-336.

Sambrook, T.D., Whiten, A. \& Strum, S.C. (1995). Priority of access and grooming patterns of females in a large and small group of olive baboons. - Anim. Behav. 50, p. 16671682 .

Samuels, A., Silk, J.B. \& Altmann, J. (1987). Continuity and change in dominance relations among female baboons. - Anim. Behav. 35, p. 785-793. 
Sapolsky, R.M., Alberts, S.C. \& Altmann, J. (1997). Hypercortisolism associated with social subordinance or social isolation among wild baboons. - Arch. Gen. Psychiatry 54, p. $1137-1143$.

Saunders, C.D. (1988). Ecological, social, and evolutionary aspects of baboon (Papio cynocephalus) grooming behavior. - $\mathrm{PhD}$ thesis, Cornell University.

Seyfarth, R.M. (1976). Social relationships among adult female baboons. - Anim. Behav. 24, p. 917-938.

- - (1980). The distribution of grooming and related behaviours among adult female vervet monkeys. - Anim. Behav. 28, p. 798-813.

— — \& Cheney, D.L. (1984). Grooming, alliances, and reciprocal altruism in vervet monkeys. - Nature 308, p. 541-543.

Silk, J.B. (1980). Kidnapping and female competition in captive bonnet macaques. Primates 21, p. 100-110.

- - (1982). Altruism among female Macaca radiata: explanations and analysis of patterns of grooming and coalition formation. - Behaviour 79, p. 162-188.

- _ (1992). The patterning of intervention among male bonnet macaques: reciprocity, revenge, and loyalty. - Curr. Anthropol. 33, p. 318-325.

- - (2001). Ties that bond: the role of kinship in primate societies. — In: New directions in anthropological kinship (L. Stone, ed.). Rowman and Littlefield, Boulder, CO, p. 71-92.

— - Kin selection in primate groups. - Int. J. Primatol. (in press).

— —, Cheney, D.L. \& Seyfarth, R.M. (1999). The structure of social relationships among female savannah baboons in Moremi Reserve, Botswana. - Behaviour 136, p. 679703.

Small, M.F. \& Smith, D.G. (1981). Interactions with infants by full siblings, paternal halfsiblings, and nonrelatives in a captive group of rhesus macaques (Macaca mulatta). Amer. J. Primatol. 1, p. 91-94.

Smucny, D.A., Price, C.S. \& Byrne, E.A. (1997). Post-conflict affiliation and stress reduction in captive rhesus macaques. - Adv. Ethol. 32, p. 157.

Smuts, B.B. (1983a). Dynamics of special relationships between adult male and female olive baboons. - In: Primate social relationships: an integrated approach. Blackwell Scientific, Oxford, p. 112-116.

_ - (1983b). Special relationships between adult male and female olive baboons: selective advantages.- In: Primate social relationships: an integrated approach. Blackwell Scientific, Oxford, p. 262-266.

- - (1985). Sex and friendship in baboons. - Aldine, New York.

Stammbach, E. (1978). On social differentiation in groups of captive female hamadryas baboons. - Behaviour 67, p. 332-338.

Stanford, C.B. (1992). Costs and benefits of allomothering in wild capped langurs (Presbytis pileatus). - Behav. Ecol. Sociobiol. 30, p. 29-34.

— - (1996). The hunting ecology of wild chimpanzees: implications for the evolutionary ecology of pliocene hominids. - Amer. Anthropol. 98, p. 96-113.

— —, Wallis, J., Matama, H. \& Goodall, J. (1994). Patterns of predation by chimpanzees on red colobus monkeys in Gombe National Park, Tanzania, 1982-1991. - Amer. J. Phys. Anthropol. 94, p. 213-229.

Strier, K.B. (1992). Faces in the forest - Harvard University Press, Cambridge, MA.

Strum, S.C. (1975). Life with the Pumphouse Gang: New insights into baboon behavior. Nat. Geog. 147, p. 672-691. 
— - (1987). Almost human. — Random House, New York.

Taylor, S.E., Klein, L.C., Lewis, B.P., Gruenewald, T.L., Gurung, R.A.R. \& Updegraff, J.A. (2000). Biobehavioral responses to stress in females: tend-and-befriend, not fight-orflight. - Psych. Rev. 107, p. 411-429.

Thierry, B. (1986). A comparative study of aggression and response to aggresion in three species of macaque. - In: Primate ontogeny, cognition, and social behavior (J.G. Else \& P.C. Lee, eds). Cambridge University Press, Cambridge, p. 307-313.

Tomasello, M. \& Call, J. (1997). Primate cognition. - Oxford University Press, Oxford.

Trives, R.L. (1971). The evolution of reciprocal altruism. - Q. Rev. Biol. 46, p. 35-57.

Veniegas, R.C. \& Peplau, L.A. (1997). Power and the quality of same-sex friendships. Psych. Women. Qtly. 21, p. 279-297.

de Vries, H. (1993). The rowwise correlation between two proximity matrices and the partial rowwise correlation. - Psychometrika 58, p. 53-69.

de Waal, F.B.M. (1989). Dominance 'style' and primate social organization. - In: Comparative socioecology, the behavioural ecology of humans and other mammals (V. Standen \& R.A. Foley, eds). Blackwell Scientific, Oxford, p. 243-263.

- - (1996). Good natured: the origins of right and wrong in humans and other animals. Harvard University Press, Cambridge, MA.

— - (1997a). The chimpanzee's service economy: food for grooming. — Evol. Hum. Behav. 18 , p. $375-386$.

— - (1997b). Food transfers through mesh in brown capuchins. — J. Comp. Psychol. 111, p. $370-378$.

- - (2000). Attitudinal reciprocity in food sharing among brown capuchin monkeys. Anim. Behav. 60, p. 253-261.

— — \& Aureli, F. (1996). Consolation, reconciliation, and a possible cognitive difference between macaques and chimpanzees. - In: Reaching into thought (A.E. Russon, K.A. Bard \& S.T. Parker, eds). Cambridge University Press, Cambridge, p. 80-110.

— — \& Luttrell, L.M. (1988). Mechanisms of social reciprocity in three primate species: symmetrical relationship characteristics or cognition? - Ethol. Sociobiol. 9, p. 101118.

Watts, D.P. (1998). Coalitionary mate guarding by male chimpanzees at Ngogo, Kibale National Park, Uganda. - Behav. Ecol. Sociobiol. 44, p. 43-55.

- - (2000). Grooming between male chimpanzees at Ngogo, Kibale National Park. I. Partner number and diverity and grooming reciprocity. - Int. J. Primatol. 21, p. 189210 . 